\title{
Colour and viscosity of egg yolk after addition of beetroot to feed for laying hens
}

\author{
Vladimír Kopřiva ${ }^{1}$, Pavel Suchý ${ }^{2}$ Eva Straková3, Michal Žd’árský ${ }^{1}$, Petr Dvořák ${ }^{1}$ \\ University of Veterinary and Pharmaceutical Sciences Brno, Faculty of Veterinary Hygiene and Ecology, \\ ${ }^{1}$ Department of Biochemistry and Biophysics, ${ }^{2}$ Department of Animal Husbandry and Animal Hygiene, \\ ${ }^{3}$ Department of Animal Nutrition, Brno, Czech Republic
}

Received May 23, 2013

Accepted December 12, 2013

\begin{abstract}
The colour and viscosity of egg yolk are among major indicators assessed by consumers and food technology. This study attempts to evaluate the colour and viscosity of yolk in laying hens' eggs after the addition of dried beetroot (Beta vulgaris L. ssp. esculenta var. rubra) at the amount of $1 \%$ and $2 \%$ per feeding dose (in July and August 2012). The experiment was performed on 24 hens that were divided into three groups of 8 laying hens. The preparatory phase lasted one week (standard diet), followed by four weeks during which experimental layers received a diet enriched with beetroot. Then, all layers were fed a mixture without beetroot for the following four weeks. Eggs were collected during the whole period of 8 weeks. In total, 30 eggs from each group were subjected to analysis. The colour of eggs was determined using spectrophotometry, by the Colour-guide sphere spex portable colorimeter. The results showed a significant $(P<0.05)$ increase in value $L^{*}$ of yolk colour in experimental groups whereas values a* and $b^{*}$ (indicators of the international colorimetric scale CIELAB) did not vary significantly. Similarly, specific purity $\mathrm{C}^{*}$ did not show a significant difference $(P<0.05)$ between the control and experimental groups. The egg yolk viscosity was lower in experimental groups compared to the control group but the difference was not significant. The addition of dried beetroot at the amount of 1 and $2 \%$ per feeding dose had no effect on colour and viscosity. This paper supported the null hypothesis that the addition of dried beetroot to the feeding dose at the amount of $1 \%$ and $2 \%$ has no effect on the colour and viscosity of egg yolk.
\end{abstract}

Antioxidants, CIELAB, Beta vulgaris, poultry nutrition, food technology

The colour and viscosity of egg yolk are among major indicators assessed by consumers when they evaluate the quality of eggs. Egg yolk contains 35\% of lipids, $16 \%$ of proteins and most $0.2 \%$ of lipophilic pigments including carotenoids (Kriz 1997). All egg yolk components contribute to its final colour. The effect of diet administered to laying hens is manifested by a number of colour tones, ranging from light yellow to dark orange (Lomakina and Mikova 2006). The colour of egg yolk is also affected by carotenoids, particularly lutein and zeaxanthin, and xanthophyls with their antioxidant effects. Beta vulgaris L. ssp. esculenta var. rubra contains among others also flavonoids, betanin, quercetin, and polyphenols (Lichtenthaler et al. 2005).

The term "chromaticity“ has been used to describe the properties of the source of light and express colour properties (spectral composition). Unlike the subjective perception of colour, colorities can be compared using spectrophotometric instruments with defined parameters (Dvorak et al. 2009). The results of reflection and absorption are expressed using the international colorimetric scale CIELAB (Commission Internationale de l'Eclairage 1986) which is based on differences between three elementary complementary colour pairs: red-green (value $a^{*}$ ), yellow-blue (value $b^{*}$ ) and black-white (value $\mathrm{L}^{*}$ ). The third indicator, specific lightness $\mathrm{L}^{*}$, is the function of reflectance, i.e. the ratio between the intensity of reflected light and the intensity of incident light from 0 (black) to 100 (white). The other indicators are defined by 
calculations: The distance between the two points represented by $\Delta \mathrm{E}^{*}$ (CIE total colour difference); specific purity $\mathrm{C}^{*}$ ab (the chroma of the colour) is the value by which particular colority differs from grey; the specific angle of the colour tone $h_{a b}$ (hue) is described as the name of colority in relation to colour (Dvorak et al. 2009; 2012). The diet composition is a major factor affecting the colour of egg yolk.

Viscosity as a physical indicator depends on the age of an egg, storage temperature, the $\mathrm{pH}$ value, specific weight, water content and egg stress. When assessing the viscosity of the whole egg, one should particularly consider the viscosity of egg yolk since it is usually $\times 8$ greater than the viscosity of egg white (Simeonovova et al. 2003).

The aim of this study was to find if the addition of beetroot to poultry feed affects yolk colour detected by the SIELAB system, and whether the addition of beetroot to the diet of laying hens affects the viscosity of egg yolk.

\section{Materials and Methods}

\section{Experimental design}

The experiment was performed in the accredited enclosure of the Faculty of Veterinary Hygiene and Ecology, University of Veterinary and Pharmaceutical Sciences Brno. The laying hens were reared using enriched cage technology. The experiment was performed (in July and August 2012) on 24 Isabrown hybrid hens aged 28 weeks that were divided into three groups of 8 laying hens. The groups of hens were housed in separate cages. During the experiment, laying hens received a complete commercial feeding mixture ad libitum (crude protein $159.0 \mathrm{~g} \cdot \mathrm{kg}^{-1}$, fat $25.8 \mathrm{~g} \cdot \mathrm{kg}^{-1}$, fibre $26 \mathrm{~g} \cdot \mathrm{kg}^{-1}$, ash $104.5 \mathrm{~g} \cdot \mathrm{kg}^{-1}$, Ca $33.2 \mathrm{~g} \cdot \mathrm{kg}^{-1}, \mathrm{P} 4.9 \mathrm{~g} \cdot \mathrm{kg}^{-1}, \mathrm{Mg} 3.1 \mathrm{~g} \cdot \mathrm{kg}^{-1}$ and metabolic energy $\left.11.7 \mathrm{MJ} \cdot \mathrm{kg}^{-1}\right)$. Water was administered continually ad libitum using automatic feeders. Two experimental groups received homogenized dried beetroot (Beta vulgaris L. ssp. esculenta var. rubra) at the amount of $1 \%$ (group 1 ) and $2 \%$ (group 2) in their feeding mixture. The last group was control that received only the feeding mixture without the addition of beetroot.

One week before the start of the experiment the hens were fed a standard diet. This week was followed by 4 weeks of diet enriched with beetroot. Afterwards all layers were fed a mixture without beetroot for the following 4 weeks. Eggs were collected during the whole period of 8 weeks. In total, 30 eggs (that were allowed to stand at $6{ }^{\circ} \mathrm{C}$ for $96 \mathrm{~h}$ ) from each group were subjected to analysis.

\section{Methods}

Egg yolk colour was determined first, followed by determination of yolk viscosity. Prior to measurement, egg yolk was separated from egg white and placed on a Petri dish with a diameter of $50 \mathrm{~mm}$. Then, it was mixed and covered using a thin plastic foil for wrapping food. The colour was determined using a spectrophotometric method in the CIELAB system, using the Colour-guide sphere spex portable spectrophotometer (BYK Gardner), without gloss, with the following set-up: spherical geometry - $\mathrm{d} / 8^{\circ}$, the source of light - $\mathrm{D}_{65}$, standard observer's angle $-10^{\circ}$, and the diameter of aperture $-8 \mathrm{~mm}$. All measurements were carried out $\times 3$; the mean of all three measured values was calculated to give the resultant value.

In order to compare the results, the mean values of $\mathrm{L}^{*}, \mathrm{a}^{*}, \mathrm{~b}^{*}$ coordinates were used to calculate further parameters of the CIELAB system. The distance between the two points $\triangle \mathrm{E}^{*}$ (CIE total color difference) was calculated according to the following formula: $\mathrm{DE}^{*}=\left[\left(\mathrm{DL}^{*}\right)^{2}+\left(\mathrm{Da}^{*}\right)^{2}+\left(\mathrm{Db}^{*}\right)^{2}\right]^{1 / 2}$. Chroma $\mathrm{C}^{*}$ ab is the value by which the particular colority differs from grey; it was calculated according to the following formula: $\mathrm{C}^{*}{ }_{\mathrm{ab}}=\left(\mathrm{a}^{* 2}+\mathrm{b}^{* 2}\right)^{1 / 2}$. Hue $\mathrm{h}_{\mathrm{ab}}$ is described as the name of a colour. Its value is calculated according to the following formula: $\mathrm{h}_{\mathrm{ab}}=\operatorname{tg}^{-1}\left(\mathrm{~b}^{*} / \mathrm{a}^{*}\right)$.

${ }^{\mathrm{ab}}$ Egg yolk viscosity was determined using the Rheo-viscometer. Samples in a cuvette KZ 100 were allowed to reach $20^{\circ} \mathrm{C}$. The determination of viscosity of substances in a range of 0.05 to $106 \mathrm{~Pa} \cdot \mathrm{s}$. Due to the size of the cuvette, two homogenized and tempered yolks were measured at the same time. The sample was poured into the cuvette and mixed $\times 10$ by moving a ball inside the cuvette. A total of 15 samples from each group were analysed on a particular date of collection. Viscosity was measured $\times 3$ for each sample of yolks and the arithmetic mean obtained from three measurements was used in further evaluation. A period of $40 \mathrm{~s}$ was allowed between individual measurements.

\section{Statistical analysis}

Data were statistically processed for each indicator $\left(\mathrm{L}^{*}, \mathrm{a}^{*}, \mathrm{~b}^{*}\right)$ and viscosity (Table 1 and Figs $\left.1-3\right)$. The dependence of egg yolk colour indicators and viscosity on the addition of beetroot in a feeding dose was tested by using one-factor ANOVA (MS EXCEL 2003). Dependences of the above-mentioned factors on the laying period were based on the mean values in individual collection cycles using two-factor ANOVA. Since we did not expect large differences among experimental groups, null hypothesis (feeding the laying hens with a diet supplemented with beetroot does not affect colour or viscosity of egg yolk) was established for the level of significance $\alpha=0.05$. 


\section{Results}

Table 1 provides an overview of colour and viscosity indicators monitored during the 8-week experimental period. Egg yolks in experimental groups were lighter. Viscosity in experimental groups was lower than that in the control group but the difference was nonsignificant. Standard error of the mean (SEM) reached up to $2.5 \mathrm{~Pa} \cdot \mathrm{s}$, which represents approximately $5 \%$ of the mean values. Specific lightness of egg yolk colour, i.e. indicator $\mathrm{L}^{*}$, increased significantly $(P<0.05)$. Variation in indicator $\mathrm{L}^{*}$ with time during the experiment is illustrated in Fig. 1. The dependence of indicator $\mathrm{L}^{*}$ on the date of a laying cycle was not confirmed. Indicator a* remained unaffected, egg yolks did not show a trend towards orange colour (Table 1).

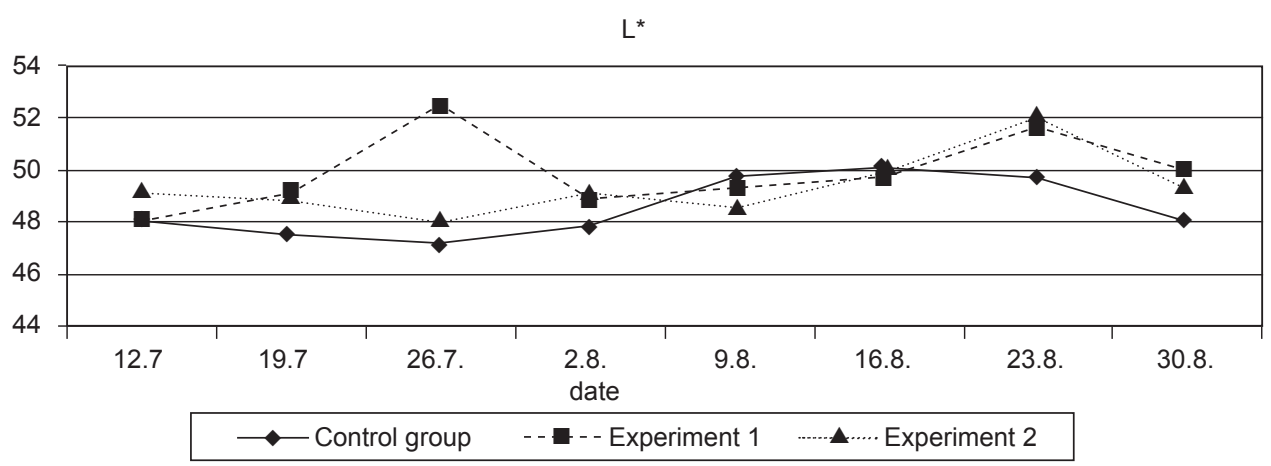

Fig. 1. Variation in value $\mathrm{L}^{*}$ with time after the addition of beetroot in the feeding dose for laying hens.

L* - indicator of the CIELAB system, Experiment 1 - hens fed with $1 \%$ of beetroot per feeding dose for laying hens, Experiment 2 - hens fed with $2 \%$ of beetroot per feeding dose for laying hens

Table 1. The effect of the addition of beetroot pigments on colour indicators and viscosity of egg yolk.

\begin{tabular}{lcccc}
\hline Groups & \multicolumn{5}{l}{} \\
\hline Indicators & Control & Experimental 1 & Experimental 2 & ANOVA \\
\hline & & $(1 \%)$ & $(2 \%)$ & $(\alpha=0.05)$ \\
$\mathrm{L}^{*}$ & $48.49 \pm 0.247$ & $49.96 \pm 0.261$ & $49.40 \pm 0.271$ & $7.557^{\mathrm{a}}$ \\
$\mathrm{a}^{*}$ & $13.30 \pm 0.197$ & $13.54 \pm 0.177$ & $13.08 \pm 0.241$ & 1.192 \\
$\mathrm{~b}^{*}$ & $38.80 \pm 0.356$ & $39.38 \pm 0.371$ & $39.95 \pm 0.348$ & 0.709 \\
$\mathrm{C}^{*}$ & 41.02 & 41.64 & 42.04 & \\
$\mathrm{~h}_{\mathrm{ab}}$ & 78.98 & 78.92 & 79.86 & \\
$\Delta \mathrm{E}^{*}$ & 0.000 & 1.598 & 1.483 & \\
Viscosity (Pa·s) & $57.28 \pm 2.399$ & $54.17 \pm 2.459$ & $52.00 \pm 2.087$ & 1.330
\end{tabular}

$\mathrm{L}^{*}, \mathrm{a}^{*}, \mathrm{~b}^{*}$ - indicators of the CIELAB system, $\mathrm{C}^{*}{ }_{\mathrm{ab}}$ - chroma, $\mathrm{h}_{\mathrm{ab}}-$ hue, $\Delta \mathrm{E}^{*}$ - CIE total colour difference. Data are expressed as mean \pm standard error of the mean, ${ }^{\mathrm{a}}$ significant differences $(P<0.05), \mathrm{F}_{(2.357)}=3.021, \mathrm{~F}_{(2.717)}=3.008$

Variation in indicator a* with time during the experiment is illustrated in Fig. 2. Indicator a* was found to depend on the date of the laying period $(P<0.05)$. This can be illustrated by comparing the results of the last two collections (Fig. 2). Indicator $b^{*}$ (yellow colour) increased slightly with the amount of beetroot in a diet. However, the corresponding 
$a^{*}$

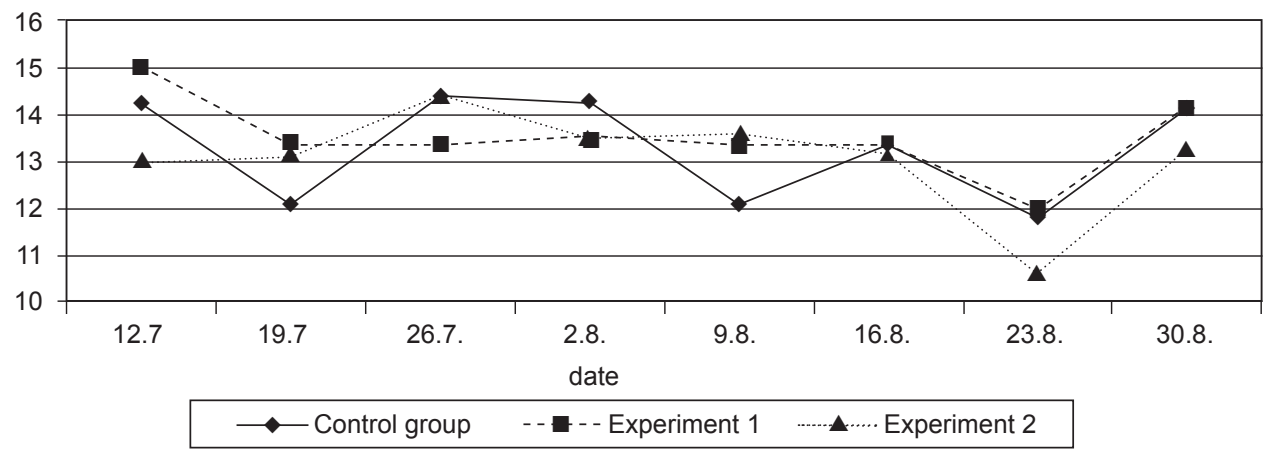

Fig. 2. Variation in value $\mathrm{a}^{*}$ with time after the addition of beetroot in the feeding dose

$a^{*}$ - indicator of the CIELAB system, Experiment 1 - hens fed with 1\% of beetroot per feeding dose for laying hens, Experiment 2 - hens fed with $2 \%$ of beetroot per feeding dose for laying hens

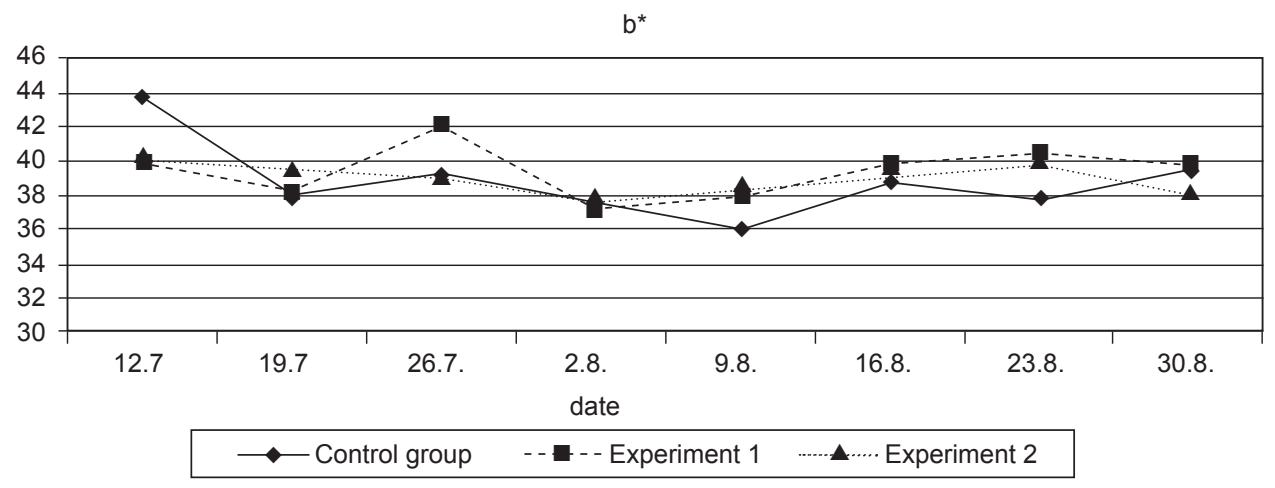

Fig. 3. Variation in value $b^{*}$ with time after the addition of beetroot in the feeding dose

$\mathrm{b}^{*}$ - indicator of the CIELAB system; Experiment 1 - hens fed with $1 \%$ of beetroot per feeding dose for laying hens, Experiment 2 - hens fed with $2 \%$ of beetroot per feeding dose for laying hens

differences were non-significant $(P<0.05)$. Variation in indicator $\mathrm{b}^{*}$ with time during the experiment is illustrated in Fig. 3. Similar to indicator $a^{*}$, indicator $b^{*}$ was also shown to correlate with the date of the laying cycle $(P<0.05)$. The most stable values were found in experimental group 2 with the feed supplemented with $2 \%$ of dried beetroot.

Calculated indicators of colority are provided in Table 1 . Hue $h_{a b}$ increased with consumed beetroot only non-significantly. Chroma $\mathrm{C}^{*}{ }_{\mathrm{ab}}$ (the value by which particular colority differs from grey) does not represent significant differences between groups. The distance between the two points $\Delta \mathrm{E}^{*}$ (CIE total colour difference) was the only indicator that differed from the control. However, the difference was higher (1.598) for the lower dose of beetroot in the diet for laying hens than for the higher dose (1.483) of beetroot. The absolute value of the difference was very low (0.115). 


\section{Discussion}

Studies conducted by other researchers (Tumova et al. 2011) as well as our previous studies (Dvorak et al. 2010) investigated the effect of housing on the quality of eggs. Our experiment compared the deep litter rearing system with the cage rearing system at the same feeding dose. During 7-month monitoring, value $b^{*}$ for egg yolk colour increased significantly from the $3^{\text {rd }}$ month in the deep litter system of rearing (Dvorak et al. 2010).

Egg yolk was therefore mixed prior to analysis. It follows from our results that the addition of dried beetroot at the amount of $1 \%$ and $2 \%$ per feeding dose caused a significant increase only in specific lightness (value $\mathrm{L}^{*}$ ). However, lighter egg yolks did not show significant changes in colority for values $a^{*}$ and $b^{*}$.

The $\Delta \mathrm{E}^{*}$ showed very small differences (1.598 and 1.483) compared to control. In comparison with our study (Dvorak et al. 2010) which compared free-range pasture of laying hens on a meadow with indoor confinement (cage technology), the value $\Delta \mathrm{E}^{*}$ was equal to 13.257. These results also indicate that receiving beetroot does not cause changes in egg yolk colour.

Lipophilic carotenoids such as lutein and zeaxanthin (Burri 1997), and xanthophylls contribute to the resultant colour of egg yolk. Factors such as diet and composition of the feeding dose are also reflected in the resultant colour. Beetroot red consists of hydrophilic pigments, particularly betanin (Goncalves et al. 2012). But even a higher concentration of this agent evidently does not affect the colour of egg yolk.

The viscosity of egg yolk decreased due to prolonged storage and heat treatment (Lucisano et al. 1996; Adamiec et al. 2002). Variation in egg yolk viscosity with the temperature and duration of storage was studied by Severa et al. (2010). Egg yolks were stored at $4-16{ }^{\circ} \mathrm{C}$ for 8 weeks. Analyses of egg yolks revealed elements of shear thinning behaviour and the presence of the shear stress limit (Severa et al. 2010). We prevented these effects to occur in our experiment by storing egg yolks only for 3 days. Although viscosity values in experimental groups dropped to $52 \mathrm{~Pa} \cdot \mathrm{s}$ compared to the control group $(57.28 \mathrm{~Pa} \cdot \mathrm{s})$, this difference was non-significant. This is probably due to the variability of the viscosity indicator.

This paper supported the null hypothesis that the addition of dried beetroot to the feeding dose at the amount of $1 \%$ and $2 \%$ has no effect on the colour and viscosity of egg yolk.

\section{Acknowledgements}

This study was funded by the grant No. MSM6215712402 from the Ministry of Education, Youth and Sport of the Czech Republic.

\section{References}

Adamiec J, Dolezal J, Mikova K, Davidek J 2002: Chenges in egg volatiles during storage. Czech J Food Sci 20: $79-82$

Burri BJ 1997: Beta-carotene and human health. A review of current research. Nutr Res 17: 547-580

CIE, Colorimetry (CIE Publications No. 15.2.) $2^{\text {nd }}$ ed. Commission Internationale de l'Eclaraige. Vienna (1986).

Dvorak P, Dolezalova J, Suchy P 2009: Photocolorimetric determination of yolk colour in relation to selected quality parameters of eggs. J Sci Food Agric 89: 1886-1889

Dvorak P, Suchy P, Strakova E, Dolezalova J 2010: Variation in egg yolk colour in different systems of reading laying hens. Acta Vet Brno 79: 13-19

Dvorak P, Suchy P, Strakova E, Kopriva V 2012: Possibilities of enhancing the colour of egg yolk. J Sci Food Agric 92: 853-856

Goncalves LCP, Trassi MAD, Lopes NB, Dorr FA, dos Santos MT, Baader WJ, Oliveira VX, Bastos EL 2012: A comparative study of the purification of betanin. Food Chem 131: 231-238

Kriz L 1997: Processing and treatment of poultry products. Mze ČR, Praha, Czech Republic, 29p.

Lichtenthaler R, Marx F 2005: Total oxidant scavenging capacities of common European fruit and vegetable juices. J Agr Food Chem 53: 103-110 
Lomakina K, Mikova K 2006: A study of the factors affecting the foaming properties of egg white - A review. Czech J Food Sci 24: 110-118

Lucisano M, Hidalgo A, Comelli EM, Rossi M 1996: Evolution of chemical and physical albumen characteristics during the storage of shell eggs. J Agric Food Chem 44: 1235-1240

Severa L, Nedomova S, Buchar J 2010: Influence of storing time and temperature on the viscosity of an egg yolk. J Food Eng 96: 266-269

Simeonovova J, Mikova K, Ingr I, Kubisova S 2003: Technology of poultry, eggs, and minor animal products (in Czech). MZLU Brno, Brno, Czech Republic, 247p.

Tumova E, Englmaierova M, Ledvinka Z, Charvatova V 2011: Interaction between housing system and genotype in relation to internal and external egg quality parameters. Czech J Anim Sci 56: 490-498 